\title{
The wintertime South Pole tropospheric water vapor column: Comparisons of radiosonde and recent terahertz radiometry, use of the saturated column as a proxy measurement, and inference of decadal trends
}

\author{
R. A. Chamberlin ${ }^{1,2,3}$ and E. N. Grossman ${ }^{1}$ \\ Received 16 March 2012; revised 22 May 2012; accepted 25 May 2012; published 7 July 2012.
}

[1] We use a fifty-year record of wintertime radiosonde observations at the South Pole to estimate the precipitable water vapor column $(P W V)$ over the entire period. Humidity data from older radiosondes is of limited reliability; however, we think an estimation of $P W V$ is possible using temperature data because the wintertime lower troposphere is very close to saturated. From temperature data we derived $P W V_{S A T}$ which is the $P W V$ if the troposphere was saturated over the entire column. Comparisons to recent radiosonde humidity data indicate that $P W V \simeq 0.88 P W V_{S A T}$. Since 1998 a CMU/NRAO $860 \mathrm{GHz}$ atmospheric radiometer has been operating at the South Pole producing zenith opacity data, $\tau_{o}$. It is expected that $\tau_{o} \propto P W V$, and also $\tau_{o} \propto P W V_{S A T}$, since the lower atmospheric column is near to saturation. We compare trends in $\tau_{o}, P W V_{S A T}$, and $P W V . P W V$ and $P W V_{S A T}$ showed little trend in the last fifty years, 1961 to 2010 , except perhaps in the last two decades, when $P W V_{S A T}$ was below average, followed by an increasing trend to above average. This increasing trend in the last decade was also observed in $\tau_{o}$, except for the final two years when it appears that something changed in the instrument response. $P W V_{S A T}$ is a useful metric for estimating $P W V$ in the earlier years of wintertime South Pole radiosonde, and it is generally useful for evaluating the wintertime performance of radiosonde humidity and atmospheric opacity instrumentation.

Citation: Chamberlin, R. A., and E. N. Grossman (2012), The wintertime South Pole tropospheric water vapor column: Comparisons of radiosonde and recent terahertz radiometry, use of the saturated column as a proxy measurement, and inference of decadal trends, J. Geophys. Res., 117, D13111, doi:10.1029/2012JD017792.

\section{Introduction}

[2] The history of water vapor over the South Pole likely has significant influence on our understanding of Antarctic water vapor transport and precipitation [Robin, 1977; Bromwich, 1988; Connolley and King, 1993; King and Turner, 1997]. Because of its dry atmosphere, in recent decades the South Pole is of great interest to submillimeter astronomers and experimental cosmologists [Carlstrom et al., 2011; Stark et al., 2001; Peterson et al., 2000; Dragovan et al., 1990]. Trends in global warming may bring higher water vapor and more precipitation to the South Pole, and may affect the future astronomical site quality [Holdaway, 2004].

\footnotetext{
${ }^{1}$ National Institute of Standards and Technology, Boulder, Colorado, USA.

${ }^{2}$ University of Colorado at Boulder, Boulder, Colorado, USA.

${ }^{3}$ Caltech Submillimeter Observatory, California Institute of Technology, Pasadena, California, USA.

Corresponding author: R. A. Chamberlin, National Institute of Standards and Technology, 325 Broadway, Boulder, CO 80305-3328, USA. (richc@boulder.nist.gov)

C2012. American Geophysical Union. All Rights Reserved. 0148-0227/12/2012JD017792
}

Increasing precipitation at the South Pole, and more generally on the Antarctic continent, influences the balance of global water retained in the polar ice cap [King and Turner, 1997]. Some recent research [Boers and van Meijgaard, 2009] suggests that trends in increasing water vapor in a cold, dry atmosphere may be very difficult to detect with even the best current radiosonde instrumentation and may take decades to show themselves. The South Pole lower troposphere, although cold, generally has quite high relative humidity. Therefore, detection of an increasing trend in water vapor abundance may be easier.

[3] Only two sites in the Antarctic interior have a long history of weather observations: South Pole and Vostok [King and Turner, 1997]. The Vostok upper air data stream apparently ceased in 1992 (see http://www.aari.aq/data/data.asp? lang $=0 \&$ station $=6$ ) making the South Pole the only interior station with a really long upper air record. Year-round radiosonde observations at the Dome $\mathrm{C}$ site were performed from 2005 to 2009 [Tomasi et al., 2011].

[4] Radiosonde humidity measurements are difficult to use for climatological studies because of varying instrument types [Elliott and Gaffen, 1991]. Humidity measurements taken in very cold and dry circumstances add to the difficulties 
[Hudson et al., 2004]. Here we extend some earlier work [Chamberlin, 2001] that attempted to look at the history of the wintertime water vapor column over the South Pole by using the saturated water vapor column, $P W V_{S A T}$, as a proxy for the water vapor column. This proxy seems reasonable since the wintertime Antarctic plateau lower and middle troposphere is often in saturation, and sometimes even in supersaturation [Schwerdtfeger, 1984; Bromwich, 1988; Gettelman et al., 2006]. The utility and validity of using $P W V_{S A T}$ as a proxy for $P W V$ was verified by comparison to millimeter-wave and submillimeter-wave ground-based radiometry measurements performed in support of South Pole radio astronomy and radio astronomy site survey [Chamberlin, 2001].

[5] An important feature of the South Pole atmosphere (and over East Antarctica in general) is the deep, low-level inversion layer [King and Turner, 1997]. At the South Pole, in wintertime, the surface is generally about $20^{\circ} \mathrm{C}$ cooler than the warmest part of the inversion layer, which is generally isothermal, relatively moist, and around 500 to $1500 \mathrm{~m}$ above the surface [Schwerdtfeger, 1984].

\section{Radiosonde}

\subsection{Radiosonde in Very Cold Weather}

[6] Year-round radiosonde observations at the South Pole have been attempted since before 1961 to the present, spanning more than 50 years. Many instrument types have been used over the years: see Table S1 in the auxiliary material. ${ }^{1}$ In general it is difficult to use archived radiosonde records in climate studies of water vapor due to changing instruments types [Elliott and Gaffen, 1991]. Measurement of water vapor in very cold temperatures, such as below $-40^{\circ} \mathrm{C}$, by radiosonde has additional problems due to reduced detector responsivity, additional hysteresis, calibration, "thermal shock" (allowing inadequate time for sensor equilibration before launch), etc. [Hudson et al., 2004; World Meteorological Organization, 1983].

[7] Concerns about accurate temperature measurement are less serious. The main problem with temperature measurement is the time constant of the detector, which is typically about 5 or 6 seconds. The balloon ascent rate is typically 3 to $6 \mathrm{~m} / \mathrm{s}$ [Hudson et al., 2004; Mahesh et al., 1997], and this lag in detector response is of interest when the radiosonde is rising through the steep inversion layer above the South Pole surface. More generally, most radiosonde temperature measurements are accurate to $\pm 0.2^{\circ} \mathrm{C}$ [Elliott and Gaffen, 1991].

[8] The record of long-term radiosonde temperature measurements is generally more credible than humidity; therefore, we suggested assuming the wintertime tropospheric water vapor column was entirely in saturation and used only the temperature profile to produce a proxy metric we called $P W V_{S A T}$ [Chamberlin, 2001]. On average, this simplification might be nearly true since during winter much of the lower atmosphere cools to the ice/water-vapor coexistence curve: i.e., it is at saturation or perhaps even sometimes in supersaturation [King and Turner, 1997; Gettelman et al., 2006]. For example, Mahesh et al. [1997] modeled the South Pole water vapor column by saturating it with respect to ice from

\footnotetext{
${ }^{1}$ Auxiliary materials are available in the HTML. doi:10.1029/ 2012JD017792.
}

the near-surface layer to above the inversion and then at $75 \%$ of saturation to the tropopause. Later, a study of the performance and record [Chamberlin, 2001] of the A.I.R. Model 4A radiosonde from 1991 to 1996 indicated we could estimate the actual wintertime water vapor column as $\sim 0.9 \times$ $P W V_{S A T}$; for an example, see Figure 4.

[9] The value in using $P W V_{S A T}$ as a proxy for wintertime South Pole water vapor column is that it might help us in interpreting the radiosonde record and in establishing if there are decade-scale trends. Also, we speculate that annual changes in $P W V_{S A T}$ might also be an indicator for annual changes in precipitation because it is an integrated measure of the saturation vapor pressure (SVP), and there is evidently a link between the SVP and Antarctic precipitation rates [Robin, 1977].

\subsection{Radiosonde Humidity Correction}

[10] Methods have been proposed to correct extreme-coldweather radiosonde humidity measurements, but they all depend on the exact instrument type and extensive field studies. We know of no corrections or detailed studies for instrument types used at the South Pole before 1991.

[11] In an earlier report [Chamberlin, 2001] we evaluated the performance of the A.I.R. Model 4A in measuring $P W V$. The A.I.R. Model 4A was used at the South Pole from 1991 to 1996. On average, and with no corrections, it compared well with 16 nearly concurrent measurements made with a NOAA radiosonde equipped with a frost point hygrometer: see Figure 1 which is reproduced from Chamberlin [2001].

[12] The cold weather performance of Vaisala instrument type RS-80 (used 2001 to 2003) was studied by Hudson et al. [2004]. That study also included the A.I.R. Models 4A and 5A. The study of the A.I.R Model 4A was based on a single sample instrument remaining from old stock at the South Pole. It did a "reasonable" job reporting the relative humidity, $R H_{w}$, down to at least $-40^{\circ} \mathrm{C}$ and with a time constant of about one half to one minute. (The average of two measurements at $-39^{\circ} \mathrm{C}$ showed a wet bias of about $8 \% R H_{w}$.) A single measurement made at $-65^{\circ} \mathrm{C}$ showed a much longer time constant, over an hour, and an extreme dry bias. Time constants of the tested RS- 80 varied from 30 seconds to 420 seconds, with a median of 140 seconds. The study of Hudson et al. confirmed the extreme dry bias of the A.I.R. Model 5A, which we reported earlier in Chamberlin [2001]. A possible limitation in all the studies is that instrument comparisons were made under relatively static conditions, and the greater ventilation that naturally occurs during the balloon ascent was not well simulated [Hudson et al., 2004].

[13] Miloshevich et al. [2006] reported that VIZ (now Lockheed Martin Sippican, Inc., Marion, Massachusetts) hygristors (probably used by the A.I.R. Model 4A) perform poorly in low-temperature, low-humidity parts of the atmosphere. In comparison, even the uncorrected RS-90 and RS-92 series radiosondes performed relatively well when $R H_{w}>20 \%$ and could be accurately corrected for very dry conditions.

[14] Given the evident limitations of the VIZ hygristors, the earlier reported agreement in $P W V$ between the NOAA frost point sonde measurements and the A.I.R. Model 4A was surprisingly good: see Figure 1. This good agreement might be attributable to the fact that the greatest contribution to $P W V$ is from the lower troposphere, where the atmosphere 


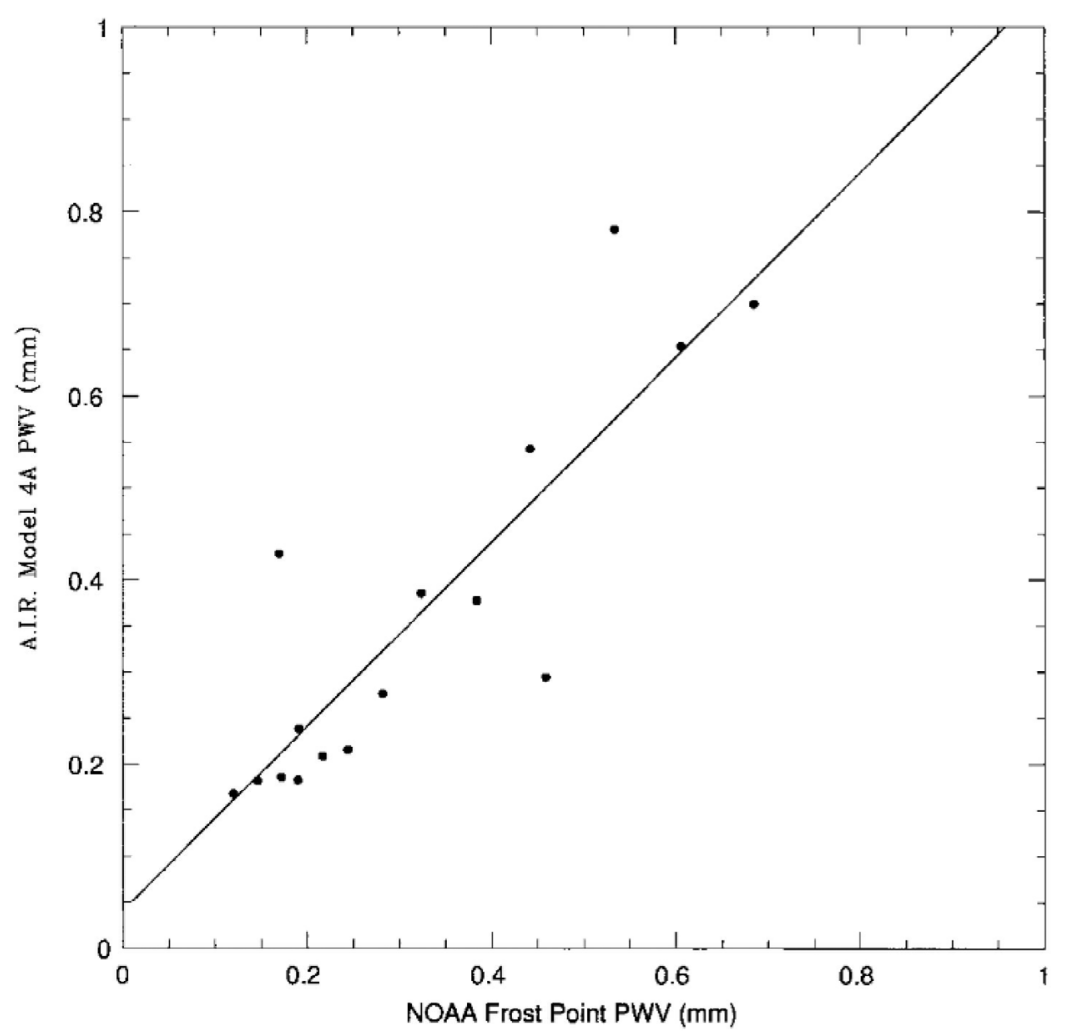

Figure 1. The $P W V$ from the A.I.R. Model 4A radiosonde was compared with 16 nearly concurrent NOAA radiosonde flights instrumented with a frost point hygrometer. The line in the plot is a least-squares fit to the data. The slope was $1.00( \pm 0.15)$ and the intercept was $0.04( \pm 0.06)$ indicating the A.I.R. Model $4 \mathrm{~A}$ may have had a slight wet bias in determining $P W V$. This figure is reproduced from Chamberlin [2001]. These data were obtained were obtained under South Pole winter and summer conditions in the years 1991 through 1994.

is relatively warm and moist, and that is the regime where VIZ hygristors can perform the best [Miloshevich et al., 2006].

[15] In all the $P W V$ results reported here, no corrections were applied to data acquired from the archives. To some extent, humidity errors caused by lag (i.e., slow response) are automatically compensated, since $P W V$ is an integrated quantity [Chamberlin, 2001]. However, future refinements could include attempting to compensate for lag and other known Vaisala errors, which for the RS-90 and RS-92 generally are not large in moist conditions. Another area for possible correction is in the formula we used to calculate the water SVP: it is Bolton's equation appropriate for the A.I.R. radiosondes, whereas the formula needed for the Vaisala radiosonde is due to Hyland and Wexler [Miloshevich et al., 2006; Hyland and Wexler, 1983]. At lower temperatures, such as at $-70^{\circ} \mathrm{C}$, Bolton's equation gives a SVP about $7 \%$ lower than the formula of Hyland and Wexler. Using the Hyland and Wexler formula on the data from Vaisala radiosondes would likely increase derived $P W V$ by a few percent.

[16] Since only one old-stock A.I.R. Model 4A sample was studied under controlled conditions by Hudson et al. [2004], not enough is known about it to attempt much in the way of compensation. The dry bias of the A.I.R. Model $5 \mathrm{~A}$ was so bad that probably no compensation scheme could help make it more realistic.
[17] In all cases, and for all years, in the derivation of $P W V_{S A T}$ we used the SVP over ice determined from an integrated form of the Clausius-Clapeyron equation [Rogers, 1976] as described in Chamberlin [2001]. At $-70^{\circ} \mathrm{C}$ this SVP was about $2 \%$ lower than the SVP determined by the formula of Hyland and Wexler [1983] and in Murphy and Koop [2005, equation 7].

\subsection{Results From Radiosonde}

[18] Figure 2 uses all of the radiosonde data available from 1961 to 2010 and gives the average $P W V_{S A T}$ (small dots, and upper curve) versus day number starting from 1 January (here 1 January, 0000 GMT is defined "Day number 1.0", etc.). (All routine radiosonde data from 1978 to present are archived at ftp://amrc.ssec.wisc.edu/pub/southpole/radiosonde. For this study radiosonde records from 1991 to 2000 were obtained directly from the South Pole Meteorology office (met@spole. gov) via ftp on or before 2001. Records prior to 1991 were obtained from the NOAA Climate Monitoring and Diagnostics Laboratory ftp site (ftp.cmdl.noaa.gov/met/raobs/spo) in 1999. This ftp site has since been reorganized, and it is not clear if the old radiosonde records are still online there. Radiosonde records from 1957 to 1960 were never located by us. The current email for South Pole meteorological information is met@usap.gov.) The smoothing curve through the points is a five-day boxcar average. $P W V$ is the lower 


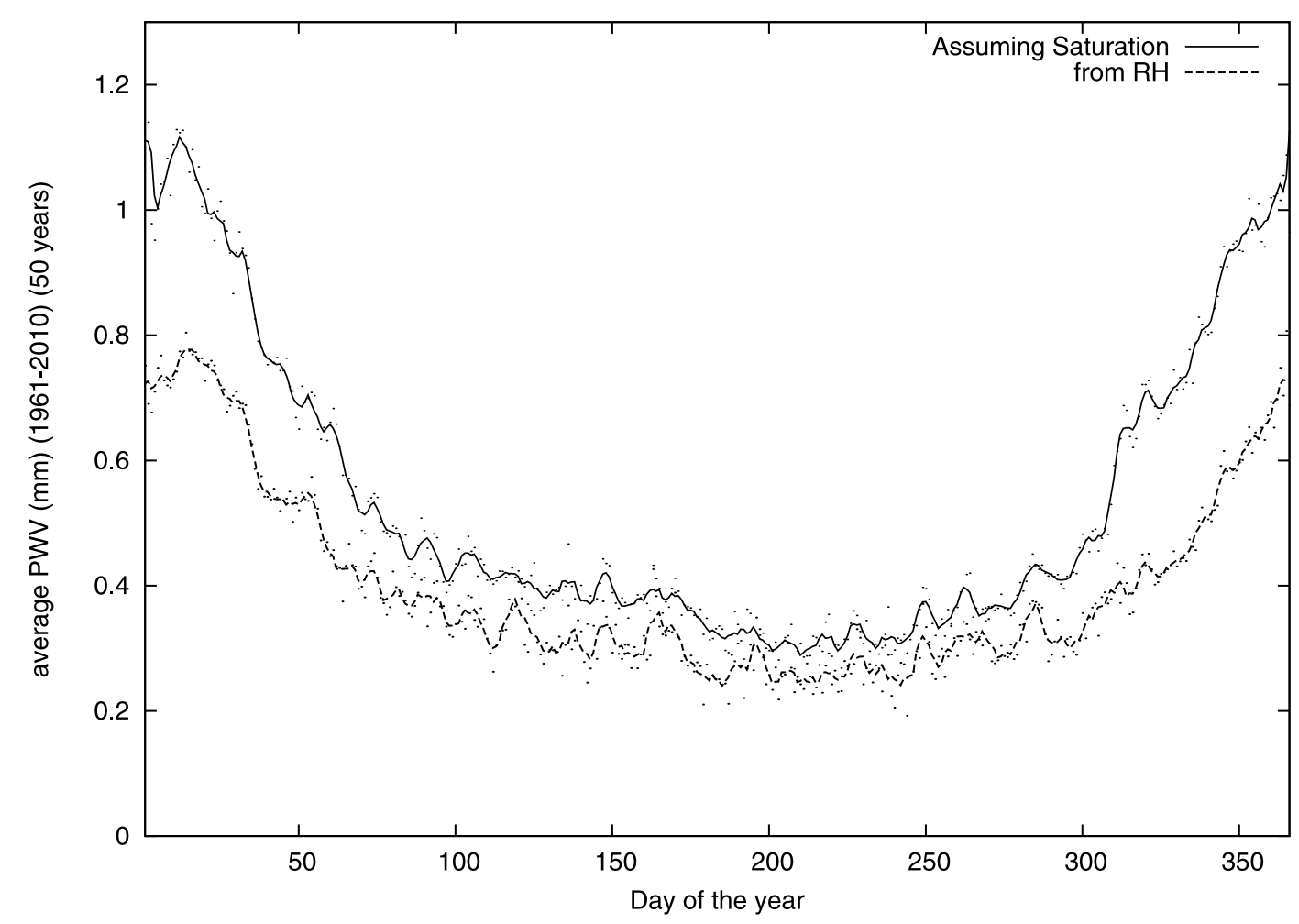

Figure 2. Fifty-year average of the South Pole tropospheric water vapor column versus day number derived from radiosondes by two methods. "Assuming Saturation" $\left(P W V_{S A T}\right)$ is the water vapor column assuming the atmosphere is in saturation and it does not rely on humidity transducer measurement. "From $\mathrm{RH}$ " $(P W V)$ is the water vapor column based upon radiosonde humidity transducer measurements. See text.

curve and heavier dots. The two curves draw near each other in wintertime, which for the purposes of this study we will define as between days 100 and 300. (Figure 2 updates Chamberlin [2001, Figures 1 and 2]. All the data were reduced as described in Chamberlin [2001].)

[19] Figure 3 shows the annual cumulative distributions for $P W V_{S A T}$ and $P W V$ for the years 1961 through 2010. For example, consider Figure 3 (top) ( " $P W V_{S A T}$ cumdist" versus Year). For the year 2010 these data show that $95 \%$ of the observed values of $P W V_{S A T}$ were below $0.81 \mathrm{~mm}$; $75 \%$ below $0.53 \mathrm{~mm} ; 50 \%$ (the median) below $0.42 \mathrm{~mm}$; and, $25 \%$ below $0.30 \mathrm{~mm}$. Figure 3 (middle) is the cumulative distribution of $P W V$ with the lines and points representing the same percentile levels as Figure 3 (top). Figure 3 (bottom) is the yearly average of the daily ratio $P W V /$ $P W V_{S A T}$. In the years 1997 to 2001 this ratio was anomalously low; these were the years when the A.I.R. Model 5A radiosonde was used. Over the years 1991 to 1996 the A.I.R Model 4A radiosonde was used, and this ratio was $0.91 \pm$ 0.07. In the years 2005 through 2010 the Vaisala RS-92 was used and the ratio was $0.86 \pm 0.08$. The combined average of the ratio from the A.I.R Model 4A radiosonde and the Vaisala RS-92 is about 0.88 .

[20] In Figure 4 we use 0.88 times the median $P W V_{S A T}$ $\left(\widetilde{P W V}_{S A T}\right)$ for estimating the median $P W V$. This estimate, $P W V_{E S T}$, is the red line (solid points) in the plot. The orange line (one-half open points) is the median $P W V$ measured by radiosonde, $(\widetilde{P W V})$. (These median values are the 50th percentile levels from Figure 3.) We show the deviation between $P W V_{E S T}$ and $\widetilde{P W V}$ in Figure 4 (bottom), which is the normalized difference, $\left(\widetilde{P W V}-P W V_{E S T}\right) / P W V_{E S T}$. The agreement is very good from the years 1991 to 1996 when the A.I.R Model 4A was in use: $4 \pm 2 \%$. For 2005 to 2010 when the Vaisala RS-92 was used the agreement was $-7 \pm 3 \%$. From 1997 to 2001 when the A.I.R. Model 5A was used the agreement was quite bad, about $-55 \%$. Since $P W V$ from years before 1991 were never cross checked in any way against other instruments we might consider them unreliable.

[21] To see if there is an apparent trend, the annual $P W V_{E S T}$ was normalized by the fifty-year average, $\left\langle P W V_{E S T}\right\rangle$ : see Figure 5. We notice the trend is below the average years for 1991 to 2001, and mostly above the average for years 2002 to 2010 . This trend may be real, or it might be attributable partly to instrument bias: years 1991 to 2001 the A.I.R. Model 4A and 5A were used; and years 2002 to 2010 the Vaisala RS-80, RS-90, and RS-92 were used. That said, the comparison of the these data to submillimeter opacity data presented in Figure 12 suggests that the generally increasing trend from 1998 through 2008 is real.

\section{Comparison With Recent Ground-Based Radiometry}

[22] Based on simple concepts such as the Beer-Lambert Law, we would expect a linear relationship between the zenith opacity coefficient, $\tau_{o}$, and the number of absorbers in an optical path length of one airmass. Of course, the 

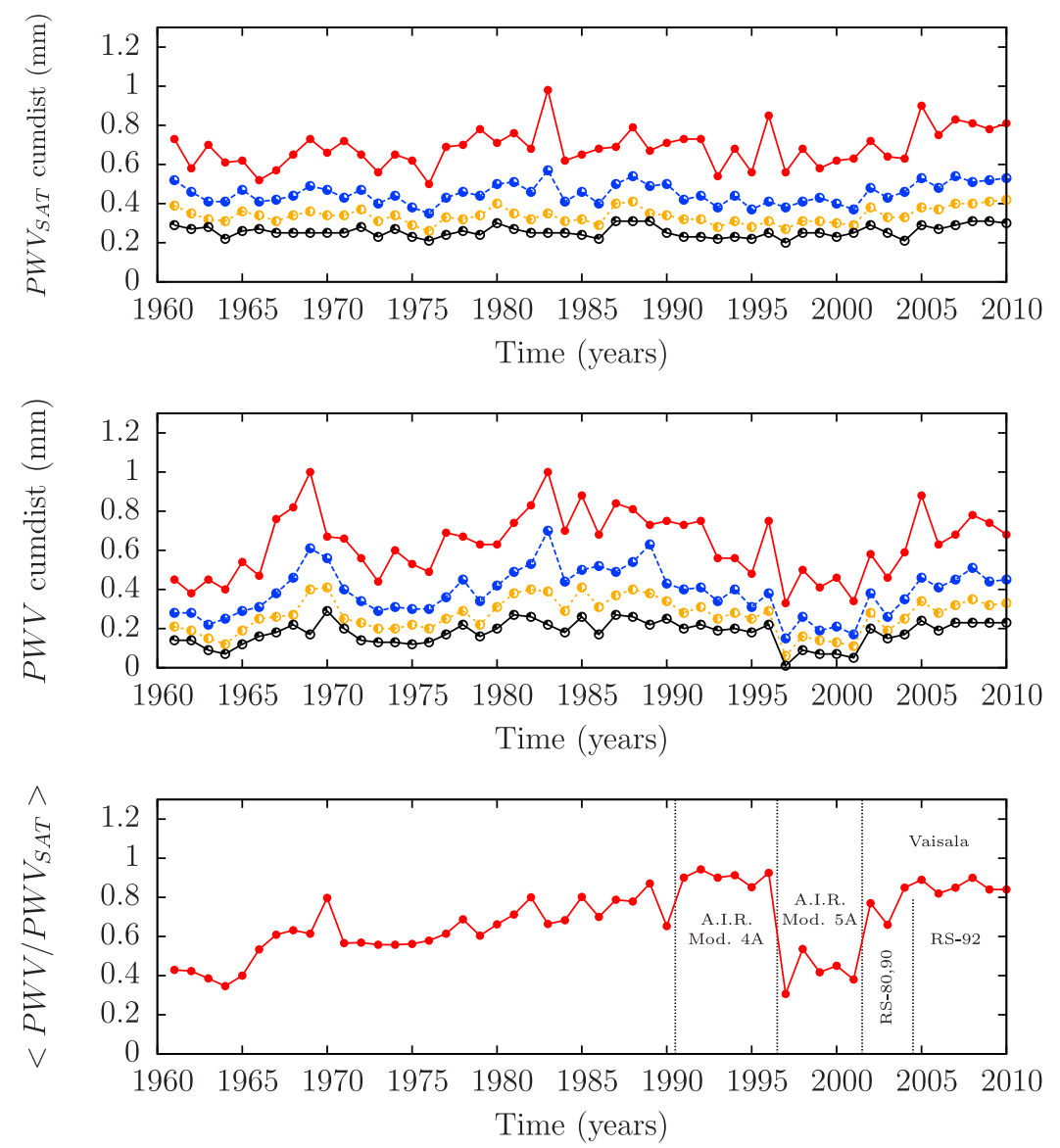

Figure 3. (top) The cumulative distribution of $P W V_{S A T}$ versus year: the connected red, solid circle points represent the 95th percentile; blue, open corner on right points represent the 75th percentile; orange, halfopen points represent the 50th percentile; black, closed corner on the left points represent the 25 th percentile. (middle) Cumulative distribution of $P W V$ with the same graphical presentation. (bottom) The yearly average of the daily ratio $P W V / P W V_{S A T}$.

absorbers (and emitters) we are concerned with are water vapor molecules, so we expect $\tau_{o} \propto P W V$. There is also a residual contribution to $\tau_{o}$ from non-water vapor molecules called "dry-air opacity".

[23] As mentioned in the abstract, a CMU/NRAO $860 \mathrm{GHz}$ atmospheric radiometer was installed at the South Pole in 1998 and operated there continually to the present. The primary purpose of this instrument is to monitor the South Pole terahertz astronomy site quality. Its radiometric passband is centered on $860 \mathrm{GHz}(\lambda=350 \mu \mathrm{m})$ and is $100 \mathrm{GHz}$ wide [Peterson et al., 2003; S. J. E. Radford et al., unpublished manuscript, 2004]. The atmospheric transmission band centered on $\sim 860 \mathrm{GHz}$ is of astronomical interest and it is bracketed by two very strong water vapor absorption/emission lines at $753 \mathrm{GHz}$ and $989 \mathrm{GHz}$. Both of these lines are in the para spin state and their opacity has been shown to be approximately linearly dependent on $R H_{w}$ at room temperature [Xin et al., 2006; Ge et al., 2009]. The water vapor opacity in the $860 \mathrm{GHz}$ band is due mainly to the pressure-broadened wings of these and other nearby water lines. The $\tau_{o}$ data presented here-but not the raw atmospheric temperature versus air mass data from which it was derived-were communicated to us by S. Radford in August 2011.
[24] The operation of this radiometer bridged the transition of four different radiosonde types: the A.I.R. Model 5A; the Vaisala RS-80; the Vaisala RS-90; and, the Vaisala RS-92. Thus, in principle, the study of its results may help us sort out some of the issues with radiosonde consistency. However, as we shall show, there were evidently some problems with the year-to-year consistency of the radiometer, particularly in the years 2009, and 2010. In the Appendix we will discuss some ways the atmospheric brightness versus airmass data can be modeled to derive $\tau_{o}$ and offer an explanation as to why the radiometer's response to atmospheric water vapor apparently changed in 2009 and 2010.

[25] The reported $\tau_{o}$ are from all-sky conditions. In the wintertime, clouds over the South Pole are thin, cirrus-like, ice clouds [Ellison et al., 2006]. The wintertime cloud fraction is estimated at $35 \%$ [Hines et al., 2004]. The ice water path (IWP) through these wintertime clouds is less than $5 \mathrm{~g} / \mathrm{m}^{2} 55 \%$ of the time [Mahesh et al., 2001]. $880 \mathrm{GHz}$ radiometric measurements of cirrus clouds at lower latitudes show that an IWP of $5 \mathrm{~g} / \mathrm{m}^{2}$ increases the sky brightness temperature by about $2^{\circ} \mathrm{K}$ [Evans et al., 1998] and we estimate it changes $\tau_{o}$ less than 0.015 which is very small compared to typical values reported here. So, for the purposes of this work, this small correction to $\tau_{o}$ is neglected. The very 

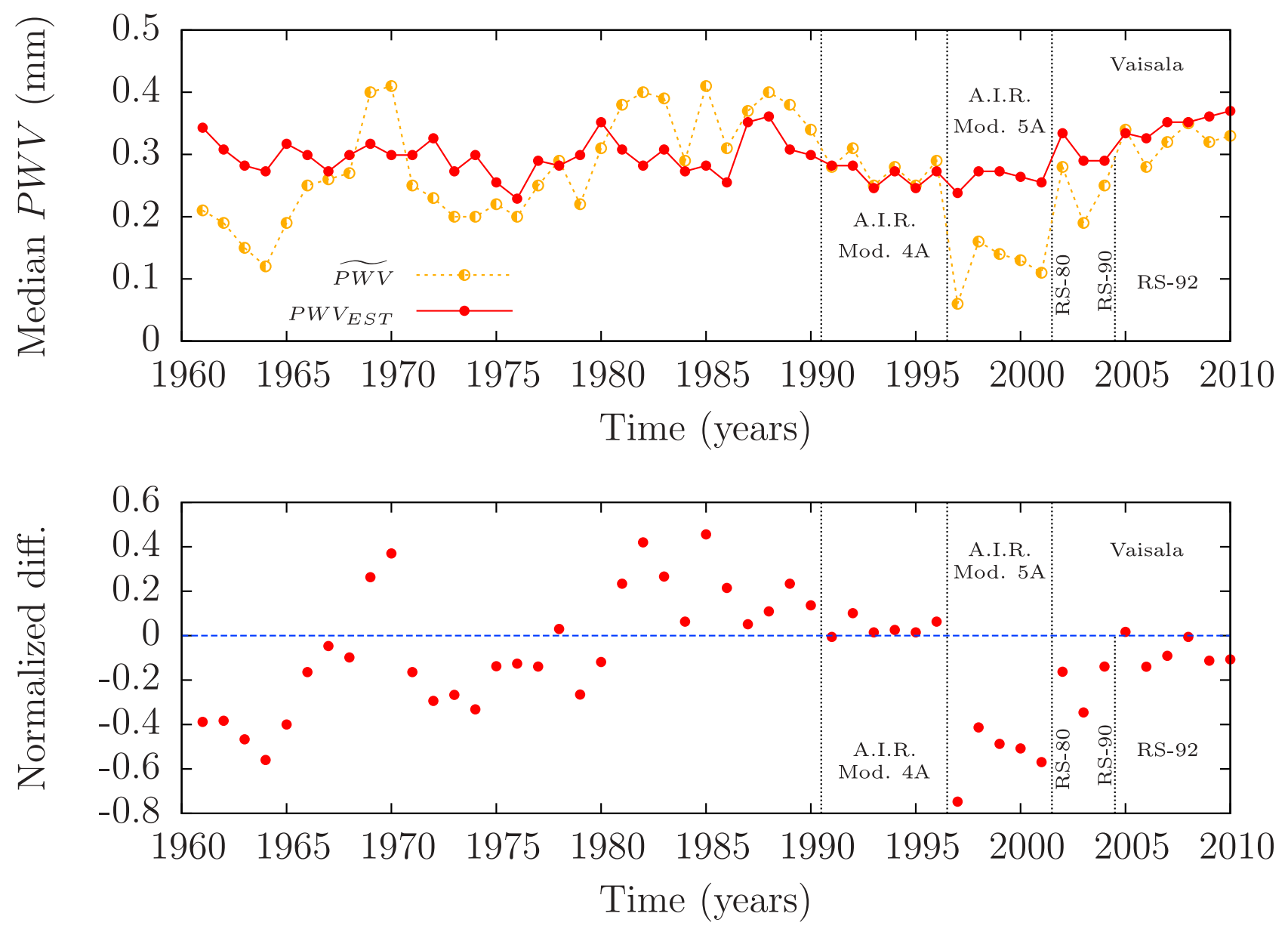

Figure 4. (top) We estimated the median $P W V$ ( $P W V_{E S T}$, red line solid points) using $0.88 * \widetilde{P W V}_{S A T}$ (see text). The median $P W V$ from the previous plot is overlaid ( $P W V$, orange line, one half open points). (bottom) The quantity $\left(\widetilde{P W V}-P W V_{E S T}\right) / P W V_{E S T}$ ("normalized diff.") is plotted to give a normalized difference between the two methods of expressing $P W V$. The agreement is very good from the years 1991 to 1996 when the A.I.R Model 4A was in use: $4 \pm 2 \%$. For 2005 to 2010 when the Vaisala RS-92 was used the agreement was $-7 \pm 3 \%$.

low submillimeter extinction caused by suspended ice particles in cirrus clouds is predicted by modeling [Liebe and Manabe, 1989].

[26] Our simulations using the am [Paine, 2012] atmospheric model indicate that changes to $\tau_{o}$ caused by changes in stratospheric ozone, or changes in surface pressure are less 0.02 which for the purposes of this study can be considered negligible.

\subsection{Zenith Opacity Versus $P W V$}

[27] In this section we will compare CMU/NRAO radiometer $\tau_{o}$ to $P W V$ from radiosonde. For some examples of earlier comparisons of South Pole submillimeter zenith opacity from other instruments to $P W V$, see Chamberlin [2001] and Chamberlin et al. [2002].

[28] Figure 6 (top) shows a short time series of the $860 \mathrm{GHz}$ zenith opacity, $\tau_{o}$, from the 2009 winter. Figure 6 (bottom) shows the $P W V$ derived from concurrent RS-92 radiosonde flights.

[29] Figure 7 is the plot of the $860 \mathrm{GHz}$ zenith opacity versus the RS-92 radiosonde derived $P W V$. The dashed line is a least-squares fit [Bevington, 1969] to the data, giving a zero intercept of $0.47 \pm 0.01$ airmass $^{-1}$, a slope of $1.92 \pm$ 0.03 airmass $^{-1} / \mathrm{mm}$, and a correlation coefficient of 0.87 with 1031 points in the fit. Only opacity data from within one hour of the radiosonde launch time was accepted. Only winter days 100 to 300 were accepted. The fit obviously is significant, but to the eye there appears to be a slight positive bias in the intercept. The positive bias is likely due to a nonsymmetric distribution of points around the best fit line: that is, we see more positive outliers above the line than below it.

[30] Like Figure 7, Figure 8 shows plots of the $860 \mathrm{GHz}$ zenith opacity versus the A.I.R. Model 5A radiosonde derived $P W V$. The plots are broken down by year from 1998 through 2001. In August 2001 the Vaisala RS-80 went into operation. Thus, year 2001 contains data from both types of radiosondes.

[31] Figures 9 and 10 are similar plots of zenith opacity versus $P W V$ for years 2002 to 2010 and for Vaisala radiosonde types RS-80, RS-90, and RS-92.

[32] Table S2 summarizes the results of the straight-line fits to the data in Figures 7-10. In all cases the correlation between $\tau_{o}$ and $P W V$ is significant but obviously not as strong in the years 1999 and 2001 when the A.I.R. Model $5 \mathrm{~A}$ was being used, probably because most of the acquired 


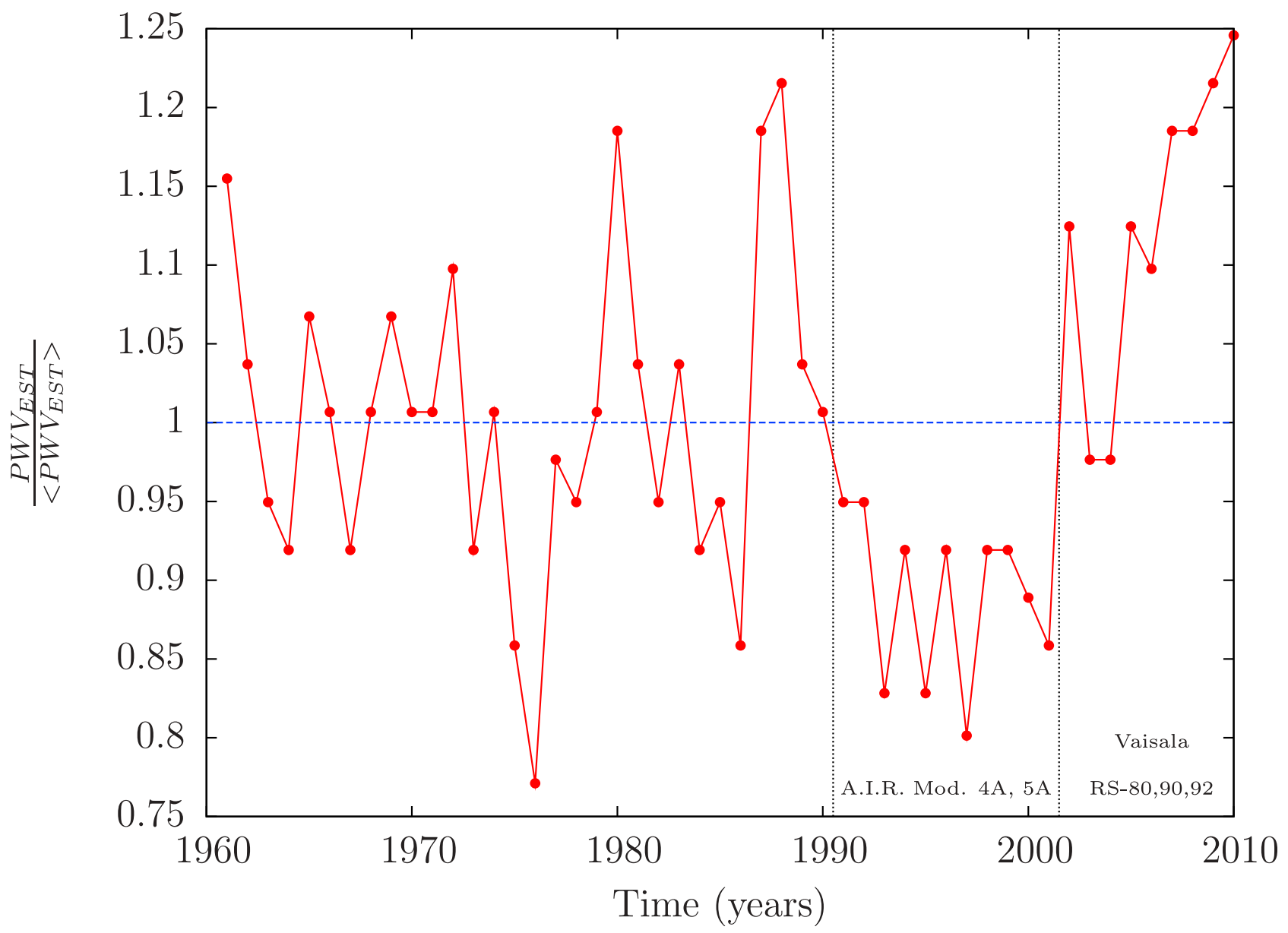

Figure 5. To help see if there is a trend, the annual $P W V_{E S T}$ is normalized by the fifty-year average, $\left\langle P W V_{E S T}\right\rangle$. We notice the trend is below the average years 1991 to 2001 and mostly above the average years 2002 to 2010 . This trend may be real, or it might be partly attributable to instrument bias: years 1991 to 2001 the A.I.R. Model 4A and 5A were used, and years 2002 to 2010 the Vaisala RS-80, RS-90, RS-92 were used. That said, the comparison of the this data to submillimeter opacity data presented in Figure 12 suggests that the generally increasing trend from 1998 through 2008 is real.

data points are clustered around the intercept, particularly in 2001. This clustering around the intercept might indicate that the radiosonde was not responsive to water vapor. The "Intercept" from the fits should give the "Dry-air opacity" and the "Slope" the dependence of $\tau_{o}$ on $P W V$. In principle, these results could be compared to atmospheric models. For example, the am model [Paine, 2012] predicts an Intercept of about 0.28 and a Slope of about 1.93. However, there is so much year-to-year variation in the Intercept and Slope that it is hard to make any comparisons with models. For example the Intercept in $2010(0.29 \pm 0.01)$ was only about one third of the value in $2005(0.90 \pm 0.01)$, even though the same type of radiosonde, RS-92, was used in both years. Averaging all years, 1998 to 2010 , gives an Intercept of $0.72 \pm$ 0.22 and a Slope of $2.00 \pm 0.55$.

[33] Referring again to Figure 10 and the correlation coefficients for those years in Table S2, we see that the straight-line fits for those years were appropriate and that derived intercept coefficients for those two years could not have been spurious. Therefore, it is valid to conclude that something significant with the instrumentation changed in the years between 2005 and 2010 .

\subsection{A Comparison of Zenith Opacity and Water Vapor Annual Statistics}

[34] Figure 11 compares of the cumulative distributions for $\tau_{o}, P W V$, and $P W V_{S A T}$ for the thirteen-year period 1998 through 2010. The definitions of the lines' percentile levels were given previously in the discussion about Figure 3. In all three panels the medians of the distributions are given by the orange line with the half open points. The A.I.R. Model 5A radiosonde was used from 1997 to 2001 , and the $P W V$ from those years is anomalously low: neither $P W V_{S A T}$, or $\tau_{o}$ indicate such a big change in water vapor column during the transition years 2001 to 2002. In the years 2009 and 2010 we note that $\tau_{o}$ seems anomalously low compared to the steady trends in $P W V_{S A T}$ and $P W V$. The radiosonde types used are indicated in Figure 11 (bottom). It is interesting that apparently we can use $P W V_{S A T}$ as a "sanity check" on other putatively more meaningful and sensitive measurements of total water vapor column. 

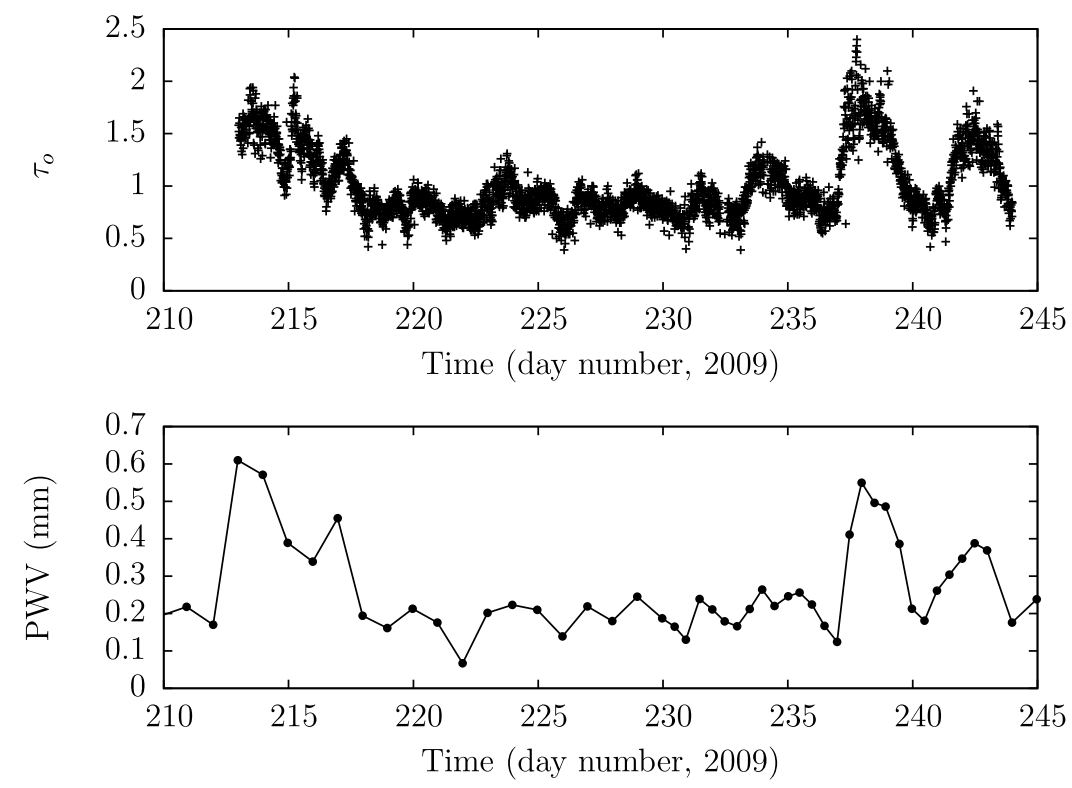

Figure 6. Time series from 2009 of $\tau_{o}$ : (top) the CMU/NRAO $860 \mathrm{GHz}$ zenith opacity and (bottom) the $P W V$ from the Vaisala RS-92 type radiosonde.

[35] In Figure 12 we compare the yearly median water vapor column estimated from $P W V_{S A T}$ (i.e, $P W V_{E S T}$ ) to the median value of $\tau_{o}$, which we denote $\widetilde{\tau_{o}}$. To put $P W V_{E S T}$ and $\widetilde{\tau_{o}}$ on a similar scale, we normalized each variable by its average value over the entire history of its measurement period. The average values are denoted by $\left\langle P W V_{E S T}\right\rangle$ and $\left\langle\widetilde{\tau_{o}}\right\rangle . P W V_{E S T} /\left\langle P W V_{E S T}\right\rangle$ and $\widetilde{\tau_{o}} /\left\langle\widetilde{\tau_{o}}\right\rangle$ seem to follow a similar trend until 2008, and then they diverge rapidly. Because both $\widetilde{\tau_{o}}$ and $P W V_{E S T}$ both roughly follow an increasing trend from 1998 to 2008 , it seems likely there was an increasing trend in the water vapor column. The change in $P W V_{E S T}$ from 1998 to 2010 was 0.0093

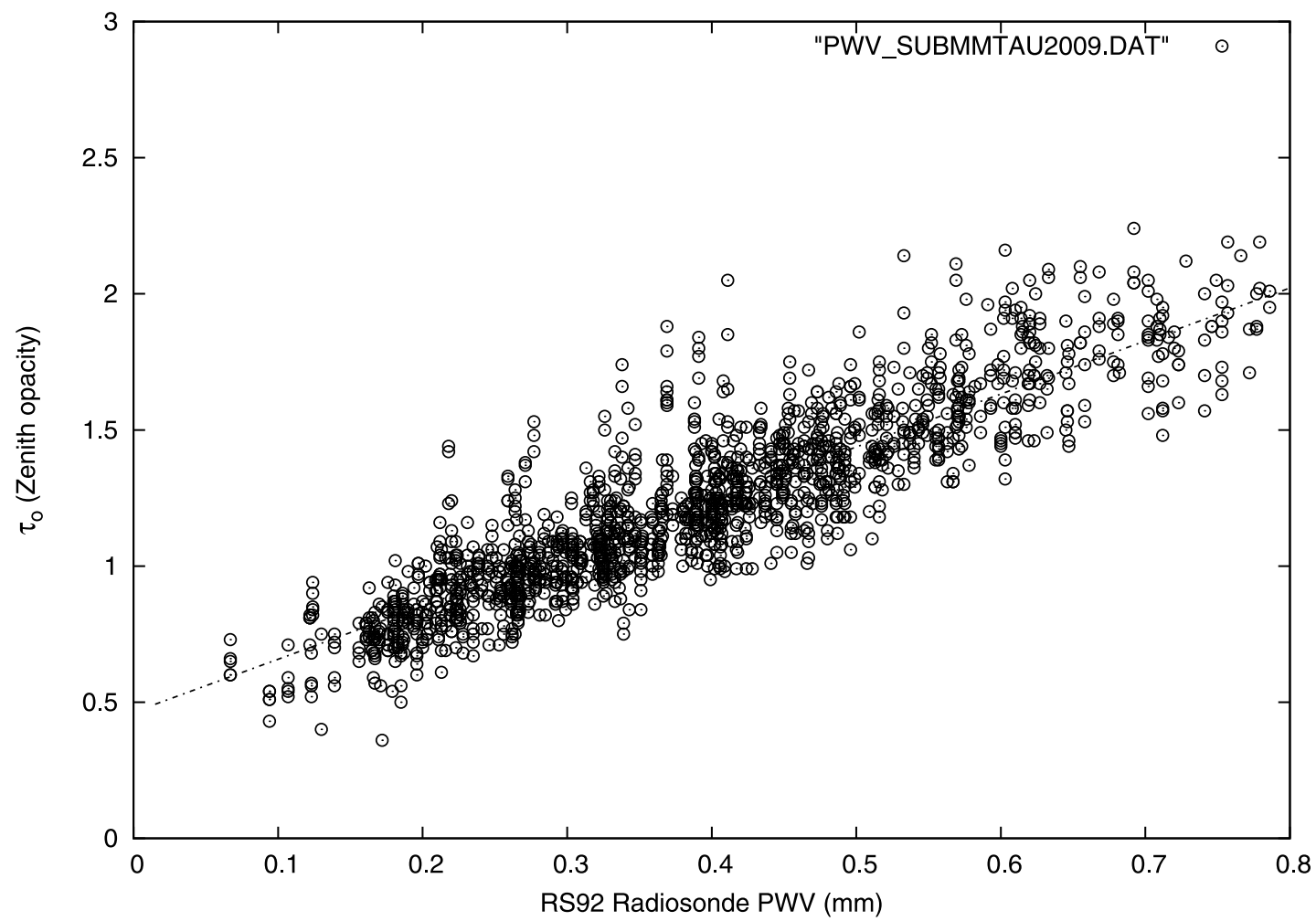

Figure 7. CMU/NRAO zenith opacity compared to $P W V$ from the Vaisala RS-92 radiosonde for wintertime days in 2009. (This plot is also reproduced in Figure 10, bottom left.) 
Wintertime Submm opacity compared to A.I.R. Model 5A PWV

1998

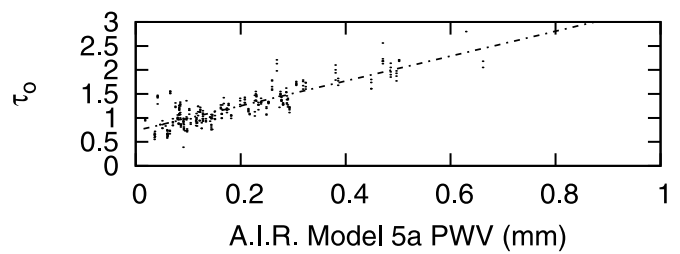

2000

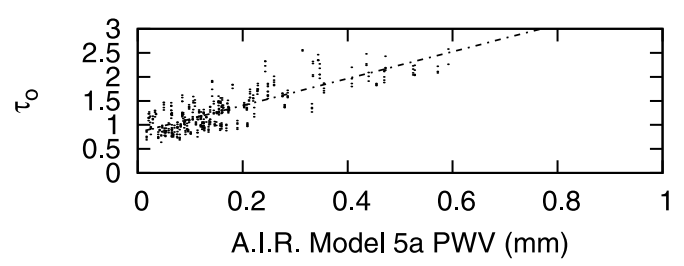

1999

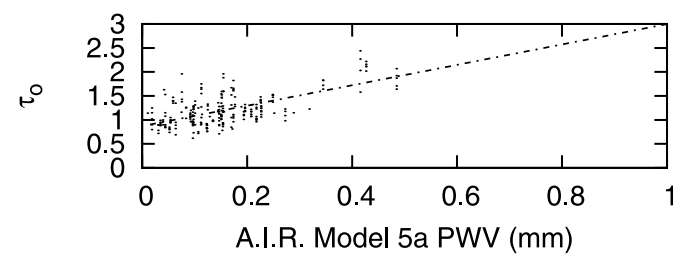

2001

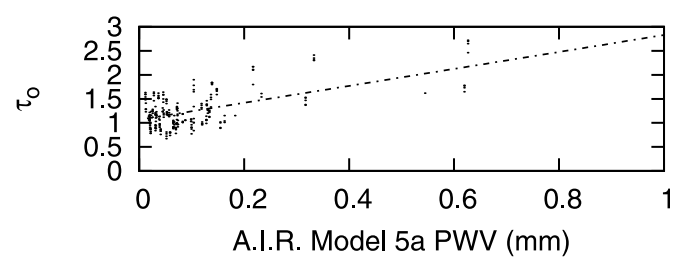

Figure 8. CMU/NRAO zenith opacity compared to $P W V$ from the A.I.R. Model 5A radiosonde. Only wintertime days are included in the scatterplots.

$( \pm 0.0014) \mathrm{mm} / \mathrm{yr}$, see " $P W V_{E S T}$ trend line" in the plot. The linear correlation coefficient for this trend line is 0.895 , and a t-test indicates that the probability of the null hypothesis explaining this data (i.e., no trend) is less than $0.01 \%$.

[36] From 1961 to 1990 (Figure 5) a linear fit indicates the trend in $P W V_{E S T}$ was $0.0002( \pm 0.0006) \mathrm{mm} / \mathrm{yr}$. Although a very small increasing trend in $P W V_{E S T}$ is indicated, it is not statistically significant, and the null hypothesis could explain it. From 1991 to $2001 P W V_{E S T}$ was about $11( \pm 5) \%$ below the 50 -year average.

[37] In other words, the decadal changes in $P W V_{E S T}$ indicate there was a long period of basically no change in the lower troposphere, followed by an eleven-year cool period, and then followed by a fairly rapid warming trend that began around 2001. How much did the lower troposphere cool and how much did it warm? If we model the contribution to $P W V$ as entirely from the saturated inversion layer, isothermal at about $-36^{\circ} \mathrm{C}$ [Schwerdtfeger, 1984], then we can use the change in SVP to estimate the change in temperature. Using the Clausius-Clapeyron equation to relate changes in SVP to changes in temperature we find: (1) from 1961 to 1990 the temperature change was about $\approx 0.17^{\circ} \mathrm{C}\left(\approx 0.0058^{\circ} \mathrm{C} / \mathrm{yr}\right.$ ); (2) from 1991 to 2001 the temperature was $\approx 1^{\circ} \mathrm{C}$ below the 50 year average; and, (3) from the cool period to 2010 the temperature increased $\approx 2.2^{\circ} \mathrm{C}\left(\approx 0.22^{\circ} \mathrm{C} / \mathrm{yr}\right)$.

[38] If we average over the whole fifty-year period, our simple interpretation indicates a lower tropospheric warming trend of about $0.01^{\circ} \mathrm{C} / \mathrm{yr}$, but the statistical significance of the trend over the fifty-year period is low. Turner et al. [2006] report significant warming in the wintertime Antarctic troposphere at mid-levels: $\approx 0.06^{\circ} \mathrm{C} / \mathrm{yr}$ over 30 years.

Wintertime Submm opacity compared to RS-80/90 PWV
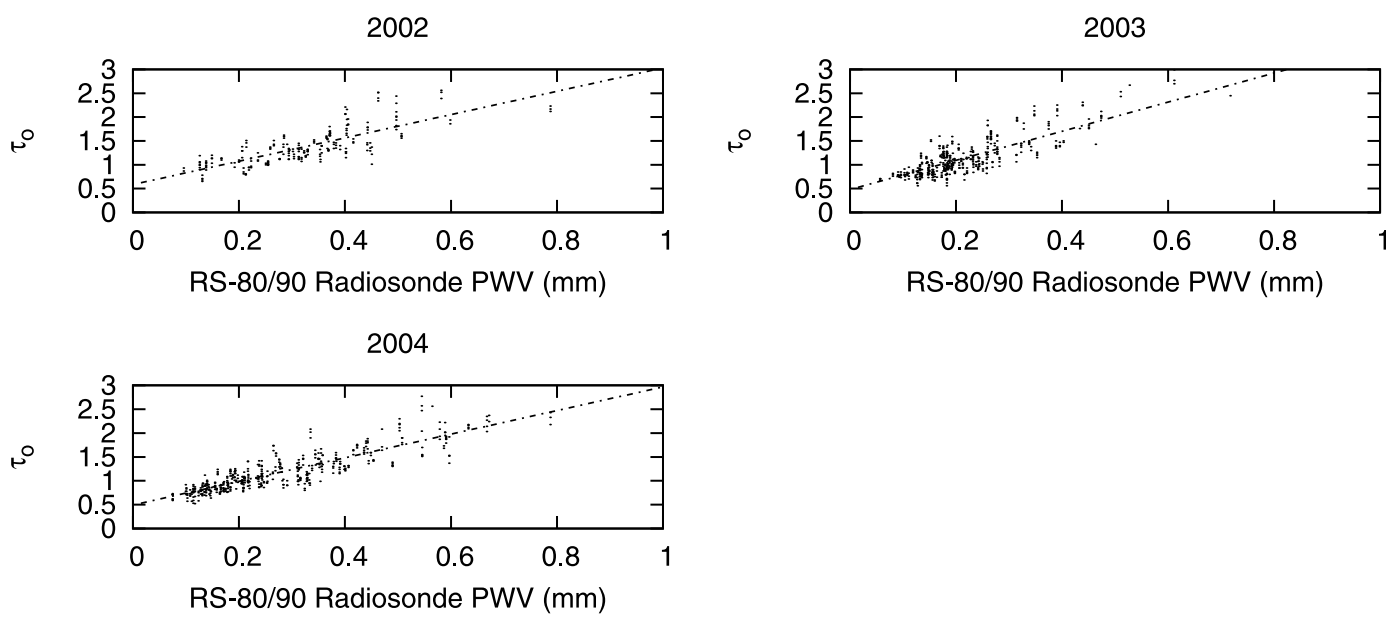

Figure 9. CMU/NRAO zenith opacity compared to $P W V$ from the Vaisala RS-80, and RS-90 radiosondes, which were used during the comparison period. Only wintertime days are included in the scatterplots. 
2005

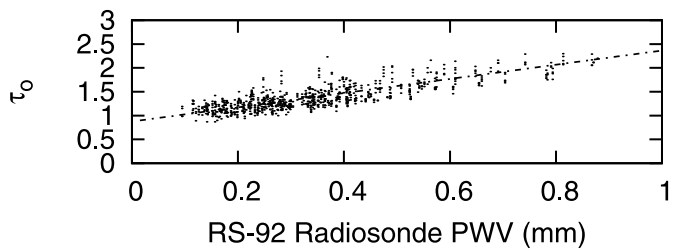

2007

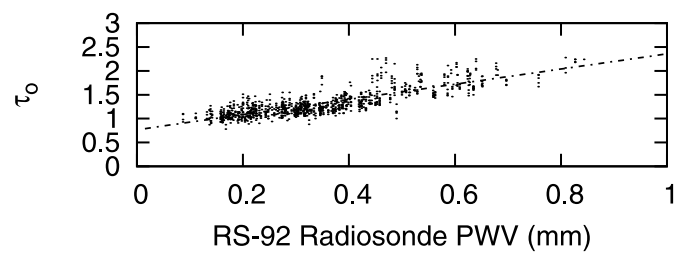

2009

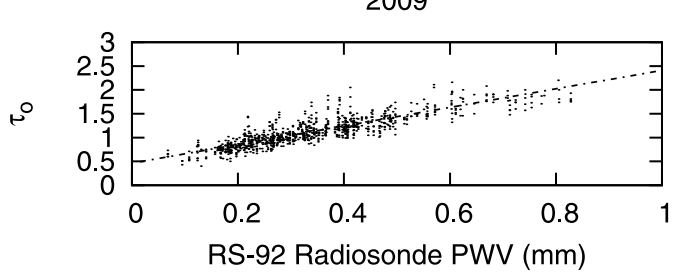

2006

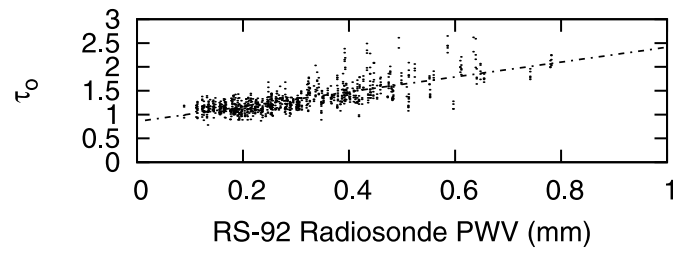

2008

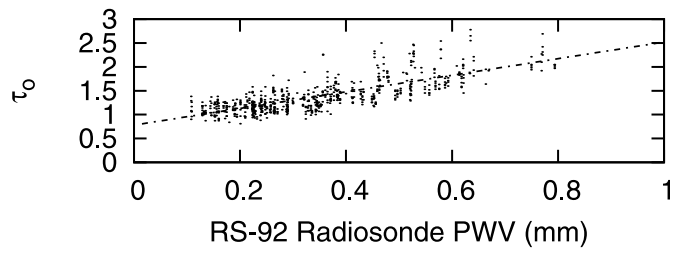

2010

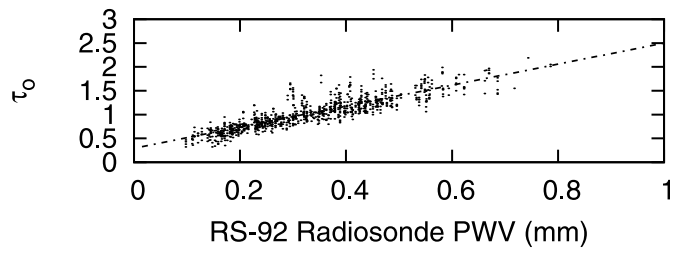

Figure 10. CMU/NRAO zenith opacity compared to $P W V$ from the Vaisala RS-92 radiosonde. Only wintertime days are included in the scatterplots. Linear regression was used to fit the data. Note that the zero intercept varies by a factor of up to three when different years are compared. For example in year 2010 the zero intercept is about 3X lower than in years 2005 and 2006.

Decadal trends in Antarctic continental surface temperature are smaller [King and Turner, 1997]: $-0.01^{\circ} \mathrm{C} / \mathrm{yr}$ for the South Pole 1957 to $1991 ; 0.025^{\circ} \mathrm{C} / \mathrm{yr}$ for Vostok Station 1958 to 1991 ; and, $0.02^{\circ} \mathrm{C} / \mathrm{yr}$ for Byrd Station 1957 to 1969 , and 1982 to 1987. Averaging reports from nine stations Turner et al. [2006] reported a wintertime warming trend of $0.015^{\circ} \mathrm{C} / \mathrm{yr}$ from 1971 to 2003 . All nine stations were near coastal areas, except for the South Pole.

[39] After 2008, and particulary in 2010, the generally lower values of $\tau_{o}$ (Figure 10), and the change in $\tau_{o}$ from trending with $P W V$ and $P W V_{S A T}$ (Figure 11) suggest that something significant changed in the CMU/NRAO radiometer performance. This point about the apparent change in the radiometer response is amplified in Figure 13, which compares the distributions of $\tau_{o}, P W V_{S A T}$, and $P W V$ for the years 2005 and 2010. There are two things to say about the actual water vapor column: (1) based on prior experience [e.g., Chamberlin, 2001] we do not expect the basic distribution to change much from year to year and this expectation is confirmed by looking at the distributions of $P W V_{S A T}$ and $P W V$ in Figures 13 (middle) and 13 (bottom), and (2) the $P W V_{S A T}$ and $P W V$ for 2005 and 2010 were obtained with the Vaisala RS-92 type of radiosonde, which has been well tested, found to perform consistently, and gives reliable results especially in conditions of higher $\mathrm{RH}$ [Miloshevich et al., 2006]. Therefore, we think it is very reasonable to conclude that something significant changed with the CMU/NRAO radiometer in the years 2009 and
2010. One possible explanation might be that in many of the years prior to 2010 wintertime ice and/or snow built up on, or inside the instrument window; and, in the years 2009 , 2010 , for some reason this problem was not as acute: see the Appendix for more discussion.

\section{Conclusion}

[40] We have confirmed that the derived quantity $P W V_{S A T}$ is useful for helping us discriminate when data from radiosonde humidity instrumentation, or radiometer instrumentation are giving inconsistent results. In addition, there is experimental evidence that on average wintertime $P W V \approx$ $0.88 P W V_{S A T}$; so we may be able to use $P W V_{S A T}$ to explore wintertime $P W V$ trends from 1961 to the present in a consistent way without being too disturbed by changes in radiosonde models, or errors in humidity sensors. Using $P W V_{E S T}$ $\left(P W V_{E S T} \equiv 0.88 \times \widetilde{P W V} \widetilde{S A T}\right)$ : we infer basically no change in $P W V$ from 1961 to 1990 ; a slightly drier period in the 1990's; and then a strong increasing trend through 2010. An increasing trend in $P W V$ from 1998 to 2008 appears to be supported by ground-based radiometer measurements at $860 \mathrm{GHz}$. After 2008 , from comparison of the statistics of $P W V$ and $P W V_{S A T}$ to $\tau_{o}$, we think there is evidence that the response of the CMU/NRAO radiometer to water vapor changed in a large way. The observation of a possible increase in the total moisture column from 1998 to 2010 needs to be cross-checked 

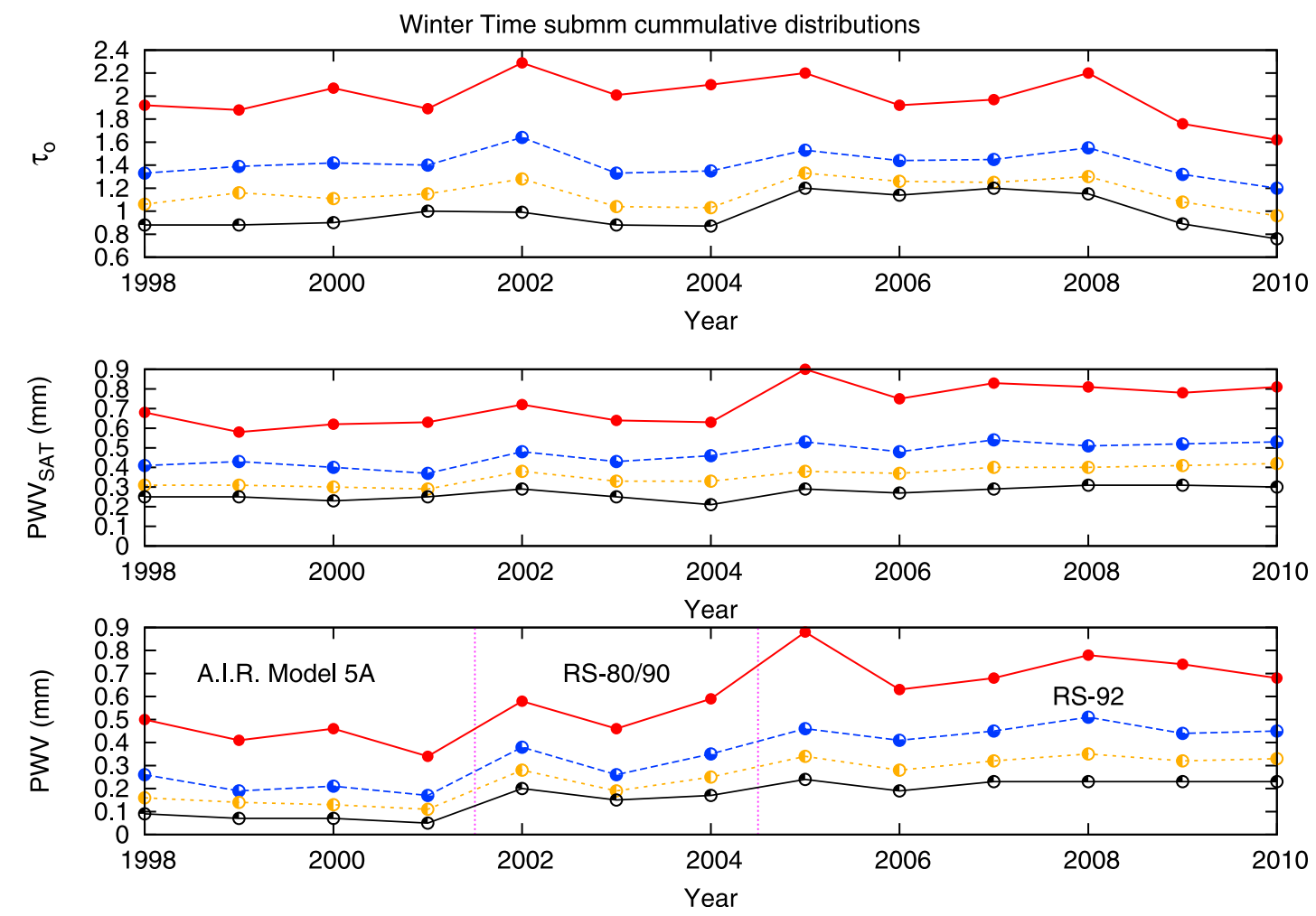

Figure 11. Comparison of cumulative distributions for the (top) $860 \mathrm{GHz}$ zenith opacity $\left(\tau_{o}\right)$, (middle) $P W V$, and (bottom) $P W V_{S A T}$ for the thirteen year period 1998 through 2010. The line and point percentile levels are defined in the caption of Figure 3. The A.I.R. Model 5A radiosonde was used from 1997 to 2001, and the $P W V$ from those years is anomalously low; neither $P W V_{S A T}$, and, as shown here, $\tau_{o}$ indicate such a low water vapor column. In the years 2009 and 2010 we note that $\tau_{o}$ seems anomalously low when compared to the steady trends in $P W V_{S A T}$ and $P W V$. The radiosonde types used are indicated in Figure 11 (bottom).

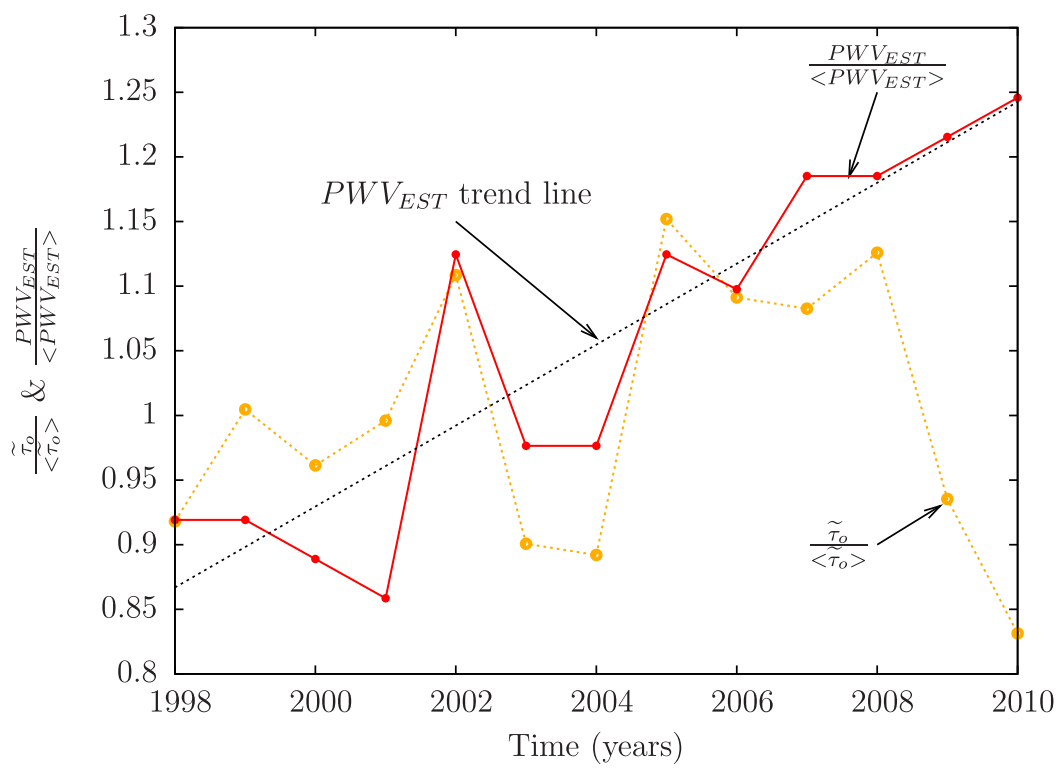

Figure 12. Comparison of $P W V_{E S T} /\left\langle P W V_{E S T}\right\rangle$ from Figure 5 and $\widetilde{\tau_{o}} /\left\langle\widetilde{\tau}_{o}\right\rangle . \widetilde{\tau}_{o}$ is the median wintertime submillimeter zenith opacity, and $\left\langle\widetilde{\tau_{o}}\right\rangle$ is the thirteen-year average from 1998 to 2010 . We see that the trends are in rough agreement, until about 2008 when they start differing greatly. Given that the year 2010 gives an unusually low $\widetilde{\tau_{o}}$, this plot suggests that something changed with the CMU/NRAO Radiometer performance in the years after 2008. From 1998-2010 the trend in $P W V_{E S T}$ is $0.009 \mathrm{~mm} / \mathrm{yr}$, as indicated by the straight line labeled " $P W V_{E S T}$ trend line". 

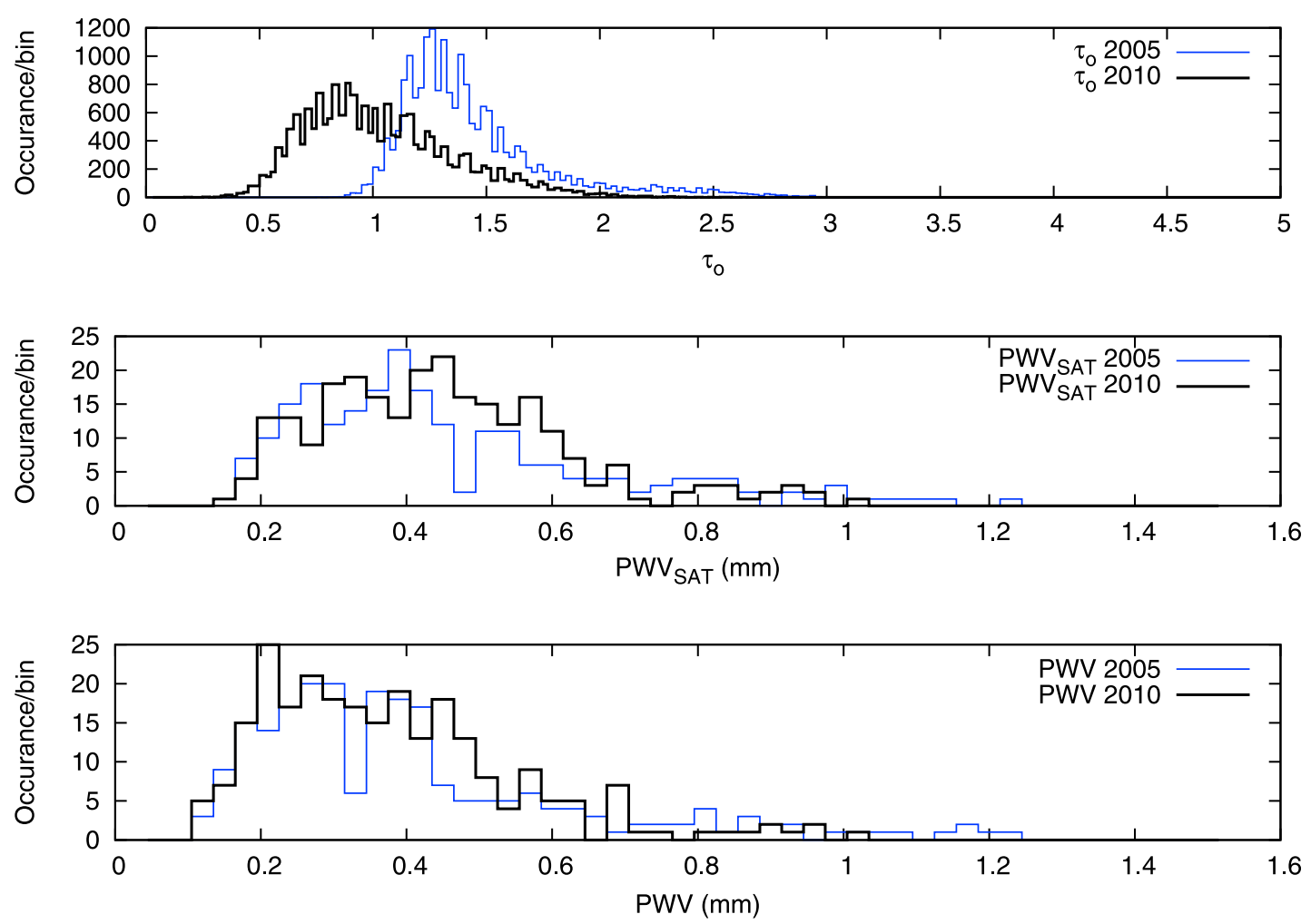

Figure 13. Comparison of 2005 and 2010 wintertime (top) $\tau_{o}$, (middle) $P W V_{S A T}$, and (bottom) $P W V$ occurrence distributions. In each plot the vertical axis is the number of occurrences per bin. In Figure 13 (top) the bin width is 0.025 zenith opacity units. In Figures 13 (middle) and 13 (bottom) the bin width is $0.03 \mathrm{~mm}$ and each "occurrence" is the average measurement per day if more than one radiosonde was launched. In each plot the light blue line represents data from 2005. The heavy black line represents data from 2010. As can be seen the $P W V_{S A T}$ and $P W V$ distributions from the two years are very similar. In contrast, there is a big shift in the $\tau_{o}$ distribution toward lower values in 2010. The comparison of these distributions reinforce our conclusion that the the CMU/NRAO radiometer response to water vapor was different in 2010 .

with available satellite data such as those used in Yang et al. [2010] and Miao et al. [2001].

\section{Appendix A}

\section{A1. Reduction of Radiometer Data}

[41] The method of reduction of data from ground-based millimeter and submillimeter radiometer instruments in Antarctica has been extensively studied at least since 1992 . As noted [Calisse, 2004], artifacts in the derived data can be caused by not accounting for instrumental effects, such as window opacity (also called "radome" effect). When the dominant loss mechanism is due to window opacity [Chamberlin, 2004; Calisse, 2004] a good model to fit the radiometer data is

$$
T_{\text {sky }}(A)=T_{\text {window }}(1-\eta)+\eta T_{\text {atm }}\left(1-e^{-\tau_{o} A}\right)
$$

where $T_{s k y}(A)$ is the radiometer sky temperature as a function of airmass $A ; T_{\text {window }}$ is the window temperature; $T_{\text {atm }}$ is the properly weighted atmospheric temperature (for more details on $T_{a t m}$, see the Appendix in Chamberlin [2004]); $\tau_{o}$ is the sky zenith opacity; and $\eta$ is the window transmission efficiency, with $\eta \equiv e^{-\tau_{\text {window }}}$, where $T_{\text {window }}$ is the window opacity. Neglecting a small correction caused by the curvature of the earth, $A=1 / \cos (Z A)$, where $Z A$ is the zenith angle of the radiometer measurement. If the window transmission was ideal, then $\eta \equiv 1$, but generally $\eta<1$. In a laboratory setting, $\eta$ for the CMU/NRAO radiometer was determined to be about 0.80 [Peterson et al., 2003; Radford et al., unpublished manuscript, 2004].

[42] $\eta$ is an instrumental constant that could be measured under controlled laboratory conditions as, was done for the results in Chamberlin et al. [2002], or it can be inferred from the zero intercept from data fitted to equation (A1), perhaps with the use of the methodology discussed in Chamberlin [2004] using only data from the best sky conditions. If derived from fitting, the most likely value of $\eta$ could then be fixed in value and then all of the data should be fit again with the only remaining free parameters being $\tau_{o}$ and perhaps $T_{a t m}$. One caveat is that if there is snow accumulation on the window, then the effective window opacity will increase. If this effect exists, it might be evident by examination of the raw CMU/NRAO $860 \mathrm{GHz}$ sky dip data if they become available. (A similar instrument was operated in Antarctica at Dome C [Calisse, 2004], and it reported "increasingly 


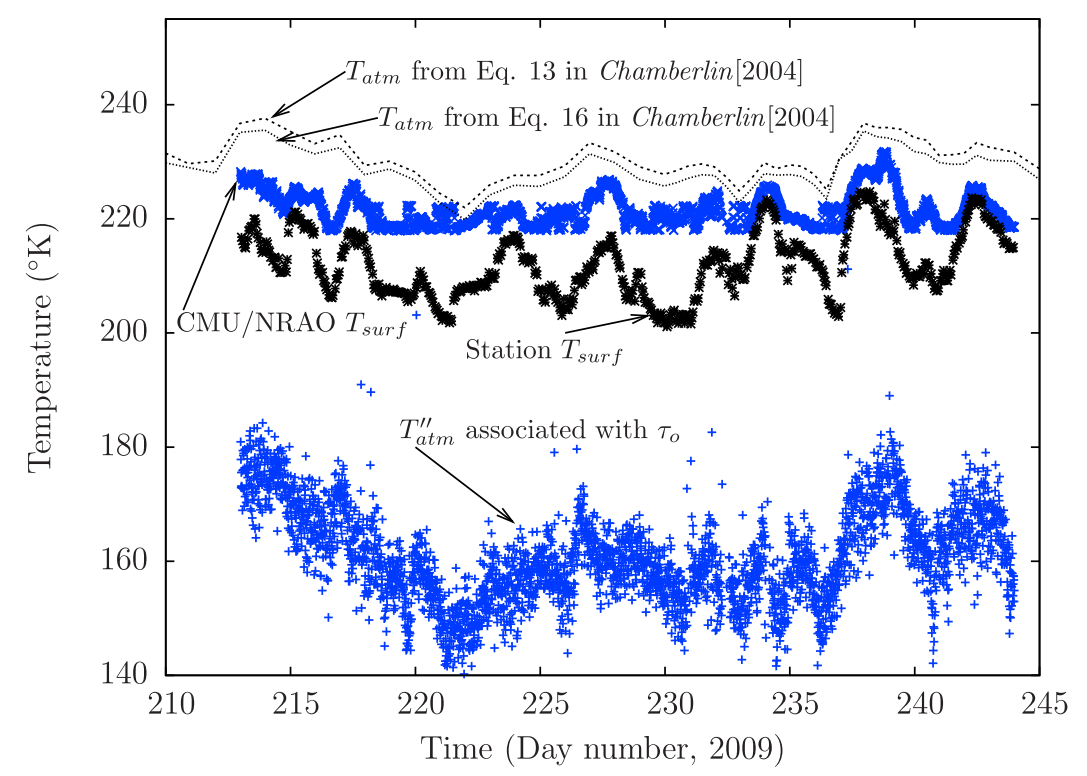

Figure A1. The atmospheric temperature from a few different methods and sources. $T_{a t m}^{\prime \prime}$ is the atmospheric temperature associated with $\tau_{o}$. It is probably derived from equation (A2) corrected by the method prescribed in Calisse [2004]. The surface temperature recorded by the South Pole meteorological office is labeled "Station $T_{\text {surf }}$ ". The surface temperature recorded by CMU/NRAO radiometer is labeled "CMU/ NRAO $T_{\text {surf }}$ ". The top two plots are $T_{\text {atm }}$ derived by use of radiosonde data and integrating the atmospheric column: (1) with use of temperature and water vapor pressure weighting $\left(T_{\text {atm }}\right.$ from Chamberlin [2004, equation 16]) and (2), with use of submillimeter opacity radiometric weighting ( $T_{\text {atm }}$ from Chamberlin [2004, equation 13]) appropriate for a relatively high-opacity passband in the atmosphere around $492 \mathrm{GHz}$. Both of these different methods of deriving $T_{\text {atm }}$ give values very close to each other and substantially greater than the surface temperature, which is expected because of the strong inversion layer that forms over the South Pole in the wintertime.

pessimistic" values of $\tau_{o}$ that were later traced to ice build-up inside the instrument window due to improper sealing.)

[43] In contrast to the model and procedures just described, consider the model [Peterson et al., 2003; Radford et al., unpublished manuscript, 2004],

$$
T_{\text {sky }}(A)=T_{\text {atm }}^{\prime}\left(1-\exp \left(-\tau_{o}^{\prime} A\right)\right),
$$

where $\tau_{o}^{\prime}$ is the $860 \mathrm{GHz}$ zenith opacity from the CMU/ NRAO atmospheric radiometer. This model is deficient in that it does not account for the instrument window opacity [Calisse, 2004]. It has been proven analytically [Calisse, 2004] that fitting $T_{\text {sky }}(A)$ data to equation (A2) always results in $\tau_{o}^{\prime}>\tau_{o}$ when $\eta<1$. Our understanding is that the $\tau_{o}$ data presented in this paper were reduced according to equation (A2) and that the window opacity was subsequently accounted for by use of the corrective methods suggested in Calisse [2004] [Peterson et al., 2003; S. Radford, private communication, 2011].

\section{A2. Atmospheric Temperature}

[44] Figure A1 is the atmospheric temperature derived from a few methods. We see that the $T_{a t m}^{\prime \prime}$ associated with $\tau_{o}$ gives a result significantly less than the surface temperature, "Station $T_{\text {surf }}$ ". This result seems unphysical since due to the deep inversion layer at the surface the wintertime $T_{a t m}$ is always greater than the surface temperature.
[45] Illustrating this expectation that $T_{a t m}^{\prime \prime}>T_{\text {surf }}, T_{\text {atm }}$ derived from concurrent radiosonde measurements are also shown [Chamberlin, 2004, equations 13 and 16].

[46] It is possible $T_{a t m}^{\prime \prime} \approx \eta T_{a t m}$, which would account for some of the discrepancy (S. Radford, private communication, 2011). The ratio $T_{a t m} / T_{a t m}$ from 1998 to 2010 is shown in Figure A2. Within the statistical variation shown by the error bars, the ratio does not change over the years: $\overline{T_{a t m}^{\prime \prime} / T_{a t m}}=$ $0.736 \pm 0.007$. This lack of variation may be a consequence of an implicit assumption that $\eta$ was constant when the

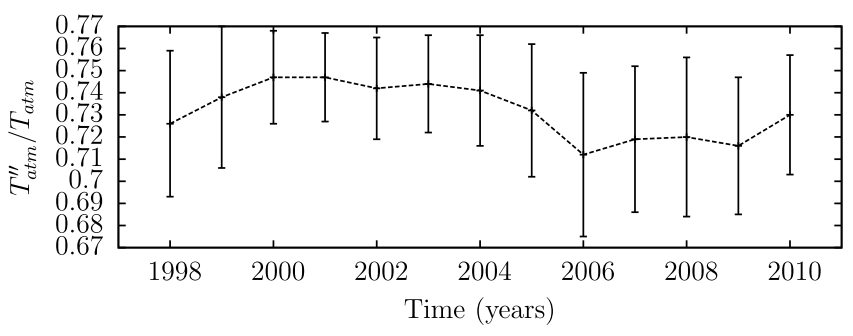

Figure A2. It can be seen that the $T_{a t m}^{\prime \prime} / T_{\text {atm }}$ does not change much over the years but that might be a consequence of an assumption that the window opacity was constant when the method of Calisse [2004] was employed to correct the result of the initial fit to equation (A2). Averaging all years, $\overline{T_{a t m}^{\prime \prime} / T_{a t m}}=0.736 \pm 0.007$, and the expressed uncertainty is the standard deviation of the mean. 


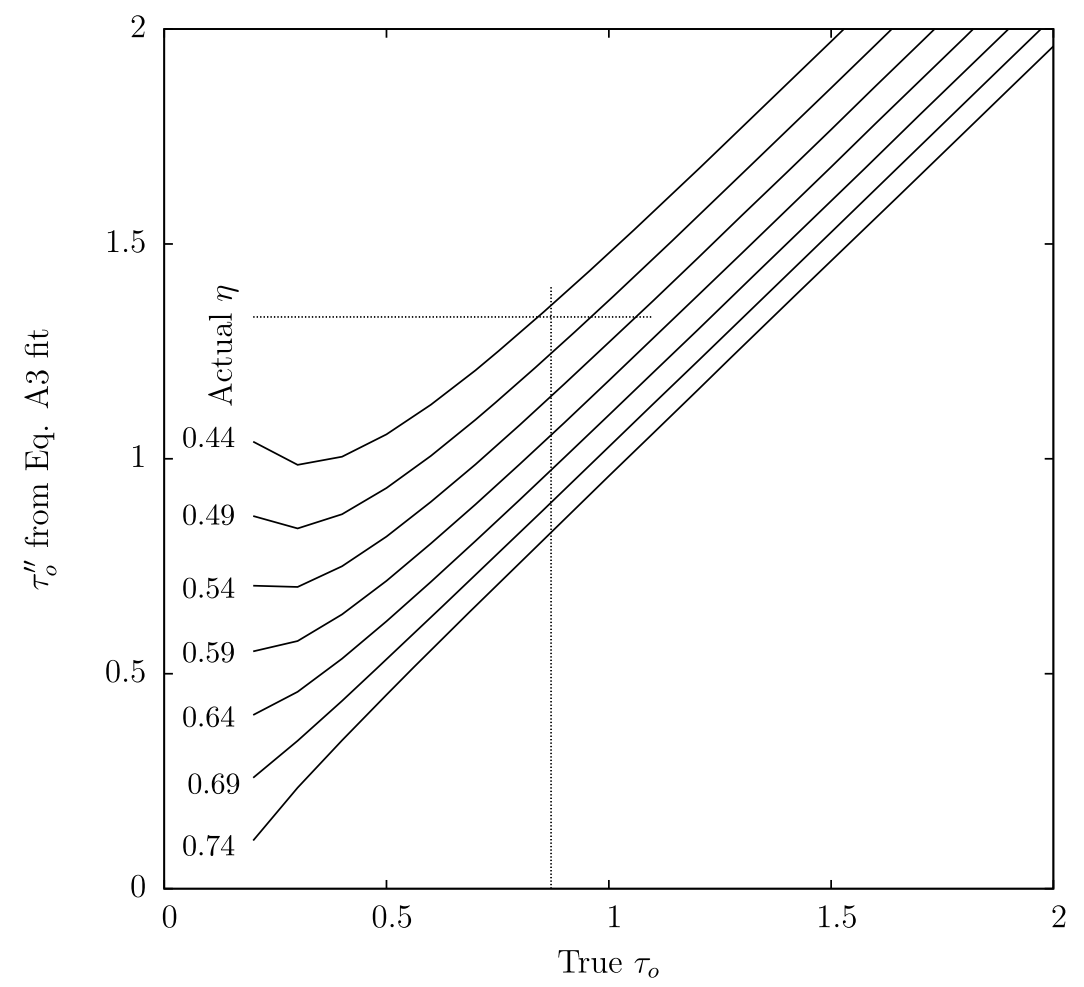

Figure A3. This figure displays the relation between the true $\tau_{o}$ and $\tau_{o}^{\prime \prime}$ as a function of the actual window transmission coefficient ("Actual $\eta$ ") based on comparisons between equations (A1) and (A3). The solid lines in the graph are the loci of constant "Actual $\eta$ ".

corrective method of Calisse [2004] was applied to the results of fitting $T_{s k y}(A)$ data to equation (A2).

[47] From Figure A1 we see a problem with the CMU/ NRAO instrument's measurement of the ambient temperature, "CMU/NRAO $T_{\text {surf }}$ ", saturating at approximately $218^{\circ} \mathrm{K}$ $\left(-55^{\circ} \mathrm{C}\right)$. We know neither the exact placement and use of this temperature transducer, or whether this saturation problem affected the instrument's calibrated measurement of the sky brightness temperature.

\section{A3. Opacity Corrections if the Window Transmission Was Less Than Modeled}

[48] Based on the previous section that examined $T_{a t m}^{\prime \prime} / T_{\text {atm }}$, we deduced that the window transmission coefficient, $\eta$, was modeled as a constant equal to about 0.74 . Therefore, the effective fitting equation was probably like

$$
T_{\text {sky }}(A)=T_{\text {window }}(1-0.74)+0.74 T_{a t m}\left(1-e^{-\tau_{o}^{\prime \prime} A}\right),
$$

which is equation (A1) with $\eta \equiv 0.74$. If, in fact the window transmission was less than 0.74 , for example due to snow and ice accumulation on or inside the window, then the $\tau_{o}^{\prime \prime}$ resulting from the fit to equation (A3) would be higher than the true $\tau_{o}$. Figure A3 displays the relation between the true $\tau_{o}$ and $\tau_{o}^{\prime \prime}$ as a function of the actual window transmission coefficient. Each of the curves in the plot is labeled on the left end with the actual $\eta$. For example, if the actual $\eta$ was 0.54 , and the true $\tau_{o}$ was 0.5 , then a fit to equation (A3) would give $\tau_{o}^{\prime \prime}=0.82$.
[49] Figure A3 was generated by first using equation (A1) to simulate true $T(A)$ data, and then least-squares fitting the simulated data to equation (A3). For the simulated data we fixed $T_{\text {window }}=T_{a t m}=236^{\circ} \mathrm{K}$, which is the approximate physical temperature of the inversion layer that contains the bulk of the water vapor. (This method is similar to the one described in Calisse [2004].)

[50] We might use Figure A3 to get a rough idea of what the actual window transmission was as follows. If in 2010 the radiometer window was ice free, then from the data in Figures 11 and 13 the true median $\tau_{o}\left(\widetilde{\tau_{o}}\right)$ was 0.96 . Following the trend of $P W V_{E S T}$ in Figure 12, the true $\widetilde{\tau_{o}}$ in 2005 was about 0.87 (vertical line in Figure A3). The 2005 data gave $\widetilde{\tau_{o}}=1.33$ (horizontal line in Figure A3). The intersection of those lines indicate that in 2005 the actual window transmission efficiency, $\eta$, was about 0.45 .

[51] Acknowledgments. We thank Simon Radford for providing the $\mathrm{NRAO/CMU} 860 \mathrm{GHz}$ zenith opacity data used in this study. We thank Steve Padin for useful discussions and for commenting on an early version of this manuscript. R.A.C. acknowledges partial support under NSF grant AST-0838261 to the Caltech Submillimeter Observatory and partial support under the CU/NIST PREP program. Any reference to a specific product or service does not constitute an endorsement by the National Institute of Standards of Technology; other vendors may supply comparable or superior products or services. NIST is a U.S. government organization; therefore, this work is not subject to copyright.

\section{References}

Bevington, P. R. (1969), Data Reduction and Error Analysis for the Physical Sciences, McGraw-Hill, New York.

Boers, R., and E. van Meijgaard (2009), What are the demands on an observational program to detect trends in upper tropospheric water vapor 
anticipated in the 21st century?, Geophys. Res. Lett., 36, L19806, doi:10.1029/2009GL040044.

Bromwich, D. (1988), Snowfall in high southern latitudes, Rev. Geophys., 26(1), 149-168, doi:10.1029/RG026i001p00149.

Calisse, P. G. (2004), The effect of a radome on submillmeter site testing measurements, Publ. Astron. Soc. Aust., 21, 252-255.

Carlstrom, J. E., et al. (2011), The 10 meter South Pole telescope, Publ. Astron. Soc. Pac., 123(903), 568-581, doi:10.1086/659879.

Chamberlin, R. A. (2001), South Pole submillimeter sky opacity and correlations with radiosonde observations, J. Geophys. Res., 106(D17), 20,101-20,113.

Chamberlin, R. A. (2004), Reanalysis of the 1992 South Pole millimetrewavelength atmospheric opacity data, Publ. Astron. Soc. Aust., 21, 264-274.

Chamberlin, R. A., R. Martin, C. L. Martin, and A. A. Stark (2002), A submillimeter atmospheric FTS at the geographic south pole, in Millimeter and Submillimeter Detectors for Astronomy, edited by T. G. Phillips and J. Zmuidzinas, Proc. SPIE Int. Soc. Opt. Eng., 4855, 609-620.

Connolley, W., and J. King (1993), Atmospheric water-vapor transport to Antarctica inferred from radiosonde data, Q. J. R. Meteorol. Soc., 119 (510b), 325-342, doi:10.1002/qj.49711951006.

Dragovan, M., A. A. Stark, R. Pernic, and M. A. Pomerantz (1990), Millimetric sky opacity measurements from the South Pole, Appl. Opt., 29(4), 463-466.

Elliott, W., and D. Gaffen (1991), On the utility of radiosonde humidity archives for climate studies, Bull. Am. Meteorol. Soc., 72(10), 15071520.

Ellison, M. E., V. P. Walden, J. R. Campbell, and J. D. Spinhirne (2006), Properties of water-only, mixed-phase, and ice-only clouds over the South Pole, paper presented at 12th Conference on Cloud Physics and 12th Conference on Atmospheric Radiation, Am. Meteorol. Soc., Madison, Wis., 10-14 July.

Evans, K. F., S. J. Walter, A. J. Heymsfield, and M. N. Deeter (1998), Modeling of submillimeter passive remote sensing of cirrus clouds, J. Appl. Meteorol., 37(2), 184-205.

Ge, J., R. Wang, S.-H. Hu, N. Dai, D. Li, H. Ma, and G.-H. Ma (2009), Investigation of the strengths of vapor rotational absorption lines with different humidity by far infrared absorption spectra, in International Symposium on Photoelectronic Detection and Imaging 2009: Terahertz and High Energy Radiation Detection Technologies and Applications, edited by X. Zhang et al., Proc. SPIE Int. Soc. Opt. Eng., 7385, 73851L, doi: $10.1117 / 12.835235$.

Gettelman, A., V. Walden, L. Miloshevich, W. Roth, and B. Halter (2006), Relative humidity over Antarctica from radiosondes, satellites, and a general circulation model, J. Geophys. Res., 111, D09S13, doi:10.1029/ 2005JD006636.

Hines, K. M., D. H. Bromwich, P. J. Rasch, and M. J. Iacono (2004), Antarctic clouds and radiation within the NCAR climate models, J. Clim., 17(6), 1198-1212.

Holdaway, M. A. (2004), Effects of global warming on precipitable water vapor above sub-millimeter wavelength astronomical sites, LAMA Memo 804, Natl. Radio Astron. Obs., Charlottesville, Va.

Hudson, S., M. Town, V. Walden, and S. Warren (2004), Temperature, humidity, and pressure response of radiosondes at low temperatures, J. Atmos. Oceanic Technol., 21(5), 825-836.

Hyland, R., and A. Wexler (1983), Formulations for the thermodynamic properties of the saturated phases of $\mathrm{H} 2 \mathrm{O}$ (from $173.15 \mathrm{~K}$ To $473.15 \mathrm{~K})$, ASHRAE Trans., 89(2A), 500-519.

King, J. C., and J. Turner (1997), Antarctic Meteorology and Climatology, Cambridge Univ. Press, Cambridge, U. K.
Liebe, H. J., and T. Manabe (1989), Millimeter-wave attenuation and delay rates due to fog/cloud conditions, IEEE Trans. Antennas Propag., 37(12), 1617-1621, doi:10.1109/8.45106.

Mahesh, A., V. P. Walden, and S. G. Warren (1997), Radiosonde temperature measurements in strong inversions: Correlation for thermal lag based on an experiment at the south pole, J. Atmos. Oceanic Technol., 14(1), 45-53.

Mahesh, A., V. P. Walden, and S. G. Warren (2001), Ground-based infrared remote sensing of cloud properties over the Antarctic plateau. Part II: Cloud optical depths and particle sizes, J. Appl. Meteorol., 40(7), 1279-1294.

Miao, J., K. Kunzi, G. Heygster, T. Lachlan-Cope, and J. Turner (2001), Atmospheric water vapor over Antarctica derived from Special Sensor Microwave/Temperature 2 data, J. Geophys. Res., 106(D10), 10,18710,203, doi:10.1029/2000JD900811.

Miloshevich, L., H. Vomel, D. Whiteman, B. Lesht, F. Schmidlin, and F. Russo (2006), Absolute accuracy of water vapor measurements from six operational radiosonde types launched during AWEX-G and implications for AIRS validation, J. Geophys. Res., 111, D09S10, doi:10.1029/ 2005JD006083.

Murphy, D. M., and T. Koop (2005), Review of the vapour pressures of ice and supercooled water for atmospheric applications, Q. J. R. Meteorol. Soc., 131, 1539-1565, doi:10.1256/qj.04.94.

Paine, S. (2012), The am atmospheric model, SMA Tech. Memo 152, Smithsonian Astrophys. Obs., Cambridge, Mass. [Available at http:// www.cfa.harvard.edu/sma/memos/152.pdf.]

Peterson, J. B., G. Griffin, M. Newcomb, D. Alvarez, C. Cantalupo, D. Morgan, K. Miller, K. Ganga, D. Pernic, and M. Thoma (2000), First results from Viper: Detection of small-scale anisotropy at $40 \mathrm{GHz}$, Astrophys. J., 532(2), L83-L86, doi:10.1086/312576.

Peterson, J. B., S. J. E. Radford, P. A. R. Ade, R. A. Chamberlin, M. J. O'Kelly, K. M. Peterson, and E. Schartman (2003), Stability of the submillimeter brightness of the atmosphere above Mauna Kea, Chajnantor, and the South Pole, Publ. Astron. Soc. Pac., 115, 383-388.

Robin, G. (1977), Ice cores and climatic change, Philos. Trans. R. Soc London, Ser. B, 280(972), 143-168, doi:10.1098/rstb.1977.0103.

Rogers, R. R. (1976), A Short Course in Cloud Physics, Pergamon, New York.

Schwerdtfeger, W. (1984), Weather and Climate of the Antarctic, Elsevier, New York.

Stark, A., et al. (2001), The Antarctic Submillimeter Telescope and Remote Observatory (AST/RO), Publ. Astron. Soc. Pac., 113(783), 567-585, doi:10.1086/320281.

Tomasi, C., B. Petkov, E. Benedetti, L. Valenziano, and V. Vitale (2011), Analysis of a 4 year radiosonde data set at Dome $\mathrm{C}$ for characterizing temperature and moisture conditions of the Antarctic atmosphere, J. Geophys. Res., 116, D15304, doi:10.1029/2011JD015803.

Turner, J., T. A. Lachlan-Cope, S. Colwell, G. J. Marshall, and W. M. Connolley (2006), Significant warming of the Antarctic winter troposphere, Science, 311(5769), 1914-1917, doi:10.1126/science.1121652. World Meteorological Organization (1983), Guide to meteorological instruments and methods of observations, WMO-No. 8, Geneva, Switzerland.

Xin, X., H. Altan, A. Saint, D. Matten, and R. R. Alfano (2006), Terahertz absorption spectrum of para and ortho water vapors at different humidities at room temperature, J. of Appl. Phys., 100(9), 094905, doi:10.1063/ 1.2357412 .

Yang, H., et al. (2010), Exceptional terahertz transparency and stability above Dome A, Antarctica, Publ. Astron. Soc. Pac., 122(890), 490-494. 